\title{
Artigos
}

\section{Os profissionais da Atenção Primária à Saúde diante das demandas de Saúde Mental: perspectivas e desafios}

Primary Health Care professionals and Mental Health demands: perspectives and challenges (abstract: p. 16)

Los profesionales de la Atención Primaria de la Salud ante las demandas de Salud Mental: perspectivas y desafíos (resumen: p. 16)

Carlos Alberto Pegolo da Gama(a)

<carlosgama@ufsj.edu.br>

Rafaela Fernandes Lourenço(b)

<rafaelaflourenco@gmail.com>

Vívian Andrade Araújo Coelho(c)

<vivian.coelho@ufop.edu.br>

Cecília Godoi Campos ${ }^{(\mathrm{d})}$

<enf.ceciliagodoi@gmail.com>

Denise Alves Guimarães ${ }^{(e)}$

<alvesguimaraesdenise@gmail.com>

\author{
(a,e) Curso de Medicina, campus \\ Centro-Oeste Dona Lindu \\ (CCO), Universidade Federal \\ de São João del-Rei (UFSJ). \\ Rua Sebastião Gonçalves \\ Coelho, 400, Bairro \\ Chanadour. Divinópolis, MG, \\ Brasil. 35501-296. \\ (b) Graduanda do curso de \\ Medicina, CCO, UFSJ. \\ Divinópolis, MG, Brasil. \\ (c) Pós-graduanda do Programa \\ de Saúde Coletiva do Instituto \\ René Rachou/Fiocruz Minas \\ (Doutorado), Escola de Medicina, \\ Universidade Federal de Ouro \\ Preto. Ouro Preto, MG, Brasil. \\ (d) Superintendência Regional de \\ Saúde de Divinópolis, Secretaria \\ Estadual de Saúde de Minas \\ Gerais. Divinópolis, MG, Brasil.
}

A atenção à Saúde Mental (SM) na Atenção Primária à Saúde (APS) é complexa e demanda integração das ações entre diversos níveis de atenção para maior efetividade. Buscou-se compreender como profissionais da APS de 11 municípios de Minas Gerais que possuíam Núcleo de Atenção à Saúde da Família (Nasf) lidavam com demandas de SM. Trata-se de estudo qualitativo, conduzido por meio de grupos focais que contaram com 134 profissionais de saúde. Os profissionais não possuíam instrumentos ou estratégias para quantificar e organizar a demanda em SM; as ações de capacitação em SM eram insuficientes; relataram dificuldades na implementação das propostas do Nasf; e identificam problemas na organização e articulação da Rede de Atenção Psicossocial (Raps) que prejudicavam a continuidade do cuidado em SM. Apesar das fragilidades apresentadas, existem reflexões em direção às mudanças da lógica tradicional biomédica em cuidados em saúde.

Palavras-chave: Saúde mental. Atenção Primária à Saúde. Apoio matricial. Educação Permanente em Saúde. Integralidade em Saúde. 


\section{Introdução}

A área de Saúde Mental (SM) coloca um grande desafio para os profissionais da Atenção Primária à Saúde (APS) devido à sua complexidade e à magnitude epidemiológica dos transtornos mentais (TM). Pesquisas apontam que existe elevada carga global de doença e grande lacuna terapêutica relacionada a esses transtornos, além da conexão entre problemas de saúde física e mental ${ }^{1}$.

As propostas de integração dos dispositivos da rede de atenção em saúde tentam facilitar a identificação precoce dos TM; o tratamento de TM comuns; o manejo clínico adequado; a referência para outros níveis quando necessário; e prevenção e promoção da SM. A integração da atenção em SM na APS deixa o cuidado mais acessível, disponível e aceito pelas comunidades e ajuda na obtenção de bons resultados clínicos².

No Brasil, o desenvolvimento de açóes de SM na APS é um processo recente e em construção. O histórico da Política de SM, iniciada na década de 1990, mostra que inicialmente priorizaram-se os pacientes com transtornos graves, em um esforço de substituição do modelo hospitalocêntrico por uma rede de serviços territorializados. Constatam-se, desde então, avanços ligados à legislação, à diminuição das internaçốes e à construção de práticas clínicas ampliadas, introduzindo o paradigma da Atenção Psicossocial ${ }^{3}$.

A partir de 2007, o Ministério da Saúde (MS) propóe uma rede de cuidados de SM incorporando a APS com a Estratégia Saúde da Família (ESF) vinculada ao território e integrada a outras políticas públicas . Em 2008, o MS propõe o Núcleo de Apoio à Saúde da Família (Nasf) objetivando ampliar a abrangência e escopo das ações da APS, bem como sua resolubilidades. Em 2011, aprofundando o processo de regionalização, o MS institui a Rede de Atenção Psicossocial (Raps) para pessoas com sofrimento psíquico, incluindo aquelas decorrentes do uso de álcool ou outras drogas ${ }^{6}$.

Existe uma confluência teórica entre as propostas da APS, do Nasf e da Raps na medida em que visam ampliar a atenção ao sofrimento psíquico, valorizando a autonomia, a inclusão social e a permanência do paciente no território. Propóem o cuidado integral, intersetorial e multiprofissional sob a lógica interdisciplinar; a instauração de relações mais horizontais dentro das equipes; e o desenvolvimento de Educação Permanente em Saúde (EPS). Esse trabalho integrado, tendo a APS como ordenadora do cuidado, objetiva buscar a articulação de ações de prevenção, promoção, tratamento e reabilitação de acordo com as necessidades do usuário.

A proposta do Nasf busca apoiar os profissionais da APS nas açốes de cuidado direto ao paciente e na organização da equipe visando à transformação do processo de trabalho; ao fortalecimento de vínculos; à criação de espaços de apoio; a construção de parcerias e da Raps; e à elaboração do diagnóstico e planejamento da situação da SM do território. São utilizados dispositivos como apoio matricial, clínica ampliada, cogestão e ferramentas que subsidiem o trabalho como o Projeto de Saúde no Território e o Projeto Terapêutico Singular (PTS) 5 . 
A implementação dessas propostas pode contribuir para que os usuários do sistema de saúde com algum tipo de sofrimento psíquico tenham acesso e acolhimento facilitados na APS, recebendo atenção adequada e encaminhamento para outros níveis de atenção e acompanhamento. Nesse sentido, a pesquisa proposta visa mostrar aos atores sociais envolvidos os diversos aspectos desse processo e os desafios de oferecer uma rede de serviços adequadas à complexidade das demandas em SM, minorando a lacuna existente nessa área.

Considerando a importância do Nasf na inserção de ações de SM na APS, este artigo buscou compreender como os profissionais da APS de municípios da Macrorregião de Saúde Oeste de Minas Gerais (MG) que possuem Nasf implantado lidam com as demandas de SM.

\section{Método}

Trata-se de estudo exploratório qualitativo ${ }^{7}$, com campo composto pelos 54 municípios da Macrorregião de Saúde Oeste de MG, com população estimada de 1.277.842 habitantes ${ }^{8}$, distribuídos em seis Regióes de Saúde (microrregióes). Na época da pesquisa, a macrorregião possuía 34 Nasf implantados, correspondendo a $62,96 \%$ dos municípios, sendo que $70 \%$ deles tinham menos de 20.000 habitantes. A região possuía 1,71 Caps por 100.000 habitantes, sendo que aproximadamente $15 \%$ da população não tinha referência de Caps?

Este estudo foi conduzido em parceria com a Superintendência Regional de Saúde da Secretaria Estadual de Saúde de MG (SRS/SES/MG), que auxiliou na definição dos municípios participantes da pesquisa no estabelecimento dos contatos iniciais e pactuaçóes com os coordenadores municipais da APS para organização do campo de pesquisa.

Para a composição da amostra em cada Região de Saúde, foram escolhidos dois municípios, sendo um deles o município-polo, e foi realizado sorteio para escolher o outro município. Foram excluídos da pesquisa aqueles que não possuíam Nasf implantado. Em uma das Regiôes de Saúde, não havia Nasf implantado no municípiopolo e havia somente Nasf implantado em um entre os demais municípios dessa região. Assim, a amostra final foi composta de 11 municípios, sendo cinco municípios-polo e seis municípios sorteados. Entre esses, quatro são de médio porte (acima de cinquenta mil habitantes) e sete, de pequeno porte (abaixo de cinquenta mil habitantes), variando entre três mil a 28.000 habitantes?. Vale esclarecer que, entre os municípios-polo, quatro são de médio porte e um, de pequeno porte.

Essa composição amostral buscou considerar a diversidade de realidades municipais com Nasf implantados que estão presentes na macrorregião e, nesse sentido, a opção de análise dos dados foi priorizando a Raps nas Regiôes de Saúde (microrregiôes), e não a realidade dos municípios em particular, uma vez que a diferença de porte populacional desses municípios exige que diferentes pactuaçôes regionais sejam feitas para oferecer a integralidade do cuidado.

As informaçóes foram coletadas pela técnica de grupo focal $(G F)^{10}$, entre julho a dezembro de 2017. Foram realizados $11 \mathrm{GFs}$, com duração média de uma hora e 15 minutos, em salas disponibilizadas pelas equipes de Saúde da Família (eSF). Em cada município, foi realizado um GF com profissionais da APS que recebem as açóes do Nasf. 
Solicitou-se aos coordenadores da APS dos municípios que indicassem 12 profissionais de diferentes eSF e formaçôes; atuantes há mais de um ano na APS; e que participassem com maior regularidade das açóes propostas pelo Nasf.

Foi elaborado roteiro baseado na proposta oficial do Nasf que abordou: 1) Demandas de SM e dificuldades da equipe com relação a elas; 2) Conhecimentos sobre a proposta do Nasf, expectativas e dificuldades da implementação; e 3) Estruturação da Raps e parcerias estabelecidas para lidar com as demandas em $\mathrm{SM}^{5,6}$.

A análise do material seguiu o referencial teórico da hermenêutica, considerando-se as etapas 1) ordenação dos dados, que inclui transcrição das gravaçóes, releitura do material e organização dos relatos; 2) classificação dos dados, que envolve leitura exaustiva dos textos, permitindo apreender estruturas de relevância dos atores sociais, ideias centrais que tentam transmitir e elaboração de categorias; e 3) análise final, que estabelece articulaçôes entre dados e referenciais teóricos, buscando responder aos objetivos fixados ${ }^{7}$.

Do processo de análise emergiram as seguintes categorias: demandas em SM; capacitação e EPS; a APS e o Nasf; e estruturação da RAPS. Este estudo foi aprovado pelo Comitê de Ética em Pesquisa no ano de 2015 (parecer n. 1.286.343), foi estabelecido contrato de sigilo, os profissionais assinaram o Termo de Consentimento Livre e Esclarecido (TCLE), as reuniôes foram gravadas e o material foi transcrito.

As falas apresentadas nos resultados foram identificadas somente com a categoria profissional, de modo a preservar o sigilo dos participantes.

\section{Resultados e Discussão}

Os GFs tiveram em média 12 participantes, num total de 134 profissionais, sendo sete médicos, 23 enfermeiros, 22 técnicos de enfermagem, dois psicólogos, um nutricionista, um educador físico, 69 agentes comunitários de saúde (ACS), quatro odontologistas e cinco técnicos de saúde bucal. Foram contemplados nesse estudo 43 equipes de Saúde da Família e 11 Nasf.

Todos os participantes dos GFs eram profissionais da APS, à exceção de um psicólogo, um nutricionista e um educador físico - todos do mesmo município - que, apesar de comporem a equipe do Nasf, identificaram-se também como integrantes da equipe da APS e, por esse motivo, acreditaram que deveriam participar, argumento aceito pelos pesquisadores.

Os 11 municípios possuíam boa cobertura de APS e Nasf implantado?. Os cinco municípios-polo possuíam Caps e quatro municípios menores têm pactuado com outros municípios o acesso a Caps. Dois municípios menores não tinham essa pactuação, ficando sem retaguarda de Caps. Nenhum dos municípios do estudo possuía Caps III, nem leitos de SM em hospital geral. Somente um município-polo possuía Caps I, que é pactuado com outro município pertencente a esta mesma microrregião? 
Os referenciais teóricos utilizados foram a concepção teórico-metodológica Paideia e as construçốes teóricas ligadas à Saúde Coletiva e à Reforma Psiquiátrica ${ }^{11-13}$. São referenciais construídos simultaneamente à estruturação do Sistema Único de Saúde, têm em comum uma crítica epistemológica ao paradigma biomédico e apontam possibilidade de avanços e superação deste modelo.

O desenvolvimento de açôes de SM na APS envolve o contato das políticas e saberes relacionados à Reforma Psiquiátrica e à SM com as açóes e saberes da ESF. Essa aproximação pode potencializar transformaçôes, na medida que põe destaque em questóes psíquicas dentro das reflexôes do processo de cuidado e propicia maior apoio e formação aos profissionais, melhorando o cuidado e um uso mais eficiente e efetivo dos recursos ${ }^{11-13}$.

\section{Demandas de Saúde Mental}

Os profissionais identificam aumento das demandas de SM, mas ressaltam não possuir instrumentos ou estratégias para quantificar e organizar essa demanda. Também percebem crescimento do número de usuários em uso de medicamentos psicotrópicos, principalmente mulheres com queixas de ansiedade e depressão que utilizam antidepressivos e/ou benzodiazepínicos:

A demanda vem crescendo nos últimos anos. É percebido claramente na SM... cerca de 20 a 30\% é demanda de SM. Já chegam procurando especialista e na maioria das vezes com diagnóstico pronto de depressão, ansiedade e transtornos mentais. [...] É um número muito grande de usuários que usam ansiolíticos, né, antidepressivos, agora o uso de Haldol Decanoato injetável, é assustador. (Medicina)

Foram apontadas associaçóes entre problemas sociais, como baixa renda, desemprego, grande número de habitantes por domicílio e queixas relacionadas à SM. Os participantes percebem também uma ligação entre problemas familiares - como rupturas matrimoniais, abandono parental ou falecimentos precoces - e sintomas de ansiedade, depressão e alcoolismo (nos adultos); uso de drogas (adolescentes); e problemas na escola (crianças).

Os participantes relatam casos de violência intrafamiliar e maus-tratos infantis, mas representam situaçôes de difícil acesso, pois a própria família tende a escondê-los. Percebem diferentes formas de violência, principalmente violência psicológica dos homens com relação às mulheres e crianças. Além disso, identificam situações de violência e abandono a idosos; sintomas de ansiedade e depressão; elevada utilização de medicamentos psicotrópicos; e aumento do número de idosos diagnosticados com demência por Alzheimer. Identificam ainda demandas ligadas às dificuldades de aprendizagem em crianças, dislexia, autismo, agressividade, hiperatividade e uso de drogas.

Os participantes também mencionam crescimento do consumo de drogas lícitas e ilícitas entre adolescentes; início precoce da atividade sexual; gestação; e prostituição. Alguns participantes identificaram aumento das tentativas de autoextermínio e de suicídios consumados, mas mencionam também a dificuldade no manejo clínico do tema, além de esforços comunitários para abafar esses casos. 
Para diversos participantes, a falta de opções de retaguarda dos profissionais ou serviços especializados favorece o processo de medicalização do social. Acreditam que a baixa oferta de tratamento psicossocial e as filas de espera para atendimentos reforçam a alternativa medicamentosa na APS:

Muitas vezes o que acontece você resolve, apaga aquele fogo na hora e a pessoa deixa por isso mesmo, entendeu? Ele tá com a receitinha lá de Alprazolam, acabou, ele vai tomar aquele remédio direto e vai ficar por isso mesmo.

(Técnico de enfermagem)

A maioria dos profissionais percebe um excesso no uso de medicamentos psicotrópicos, mas não tem dados precisos sobre a parcela da população que os utiliza; afirma que os usuários não têm crítica a respeito dos problemas de dependência e efeitos colaterais associados; e acredita que esse uso já faz parte da cultura local, sendo algo difícil de mudar.

Percebe-se um despreparo dos profissionais em lidar com essa questão, pois não se colocam como corresponsáveis pela conscientização dos usuários ou pela busca de outras intervençôes psicossociais para lidar com o problema ${ }^{14}$.

Identifica-se também em muitos municípios a prática de renovação de receitas ligadas a problemas de acesso ao psiquiatra, aliado a dificuldades do médico generalista em manejar essas questóes. Esta é uma demanda comumente atendida sem maiores questionamentos, intensificando a fragmentação das intervenções em SM e a sensação de impotência dos profissionais de saúde não médicos ${ }^{15}$.

Sobre a dificuldade de acesso, considerando a macrorregião em sua totalidade, 24 municípios de pequeno porte, que correspondem à $14 \%$ da população, não possuem cobertura de Caps. Nos municípios pertencentes à amostra, apenas dois não possuem retaguarda desse serviço ${ }^{9}$. A alta rotatividade dos profissionais na APS também é apontada como um fator que compromete a qualidade da relação entre usuários e eSF ${ }^{16}$.

Em geral, os relatos apontam que há resistência, tanto dos sujeitos quanto das famílias, em procurar a APS, pois as questóes vinculadas à SM são percebidas como temas tabus que geram estigmatização e preconceito ou não são aceitas pelos sujeitos acometidos.

Ocorre também uma medicalização do sofrimento psíquico quando os profissionais detectam situaçóes estressantes sem que haja uma escuta qualificada, o que produz no longo prazo um agravamento da situação e a necessidade de encaminhamento para outros pontos de atenção ${ }^{17}$.Identifica-se também dificuldades dos profissionais no manejo de temas como sexualidade, suicídio, violência doméstica, maus-tratos e SM na terceira idade ${ }^{18}$.

Nesse sentido, apesar de a APS ser identificada como cenário propício para o cuidado em $\mathrm{SM}^{19}$, percebem-se dificuldades ligadas, principalmente, à presença hegemônica do paradigma biomédico, cujas ações são centradas no corpo, na doença e no individual. A mudança de paradigma necessitaria de uma ampliação do foco, incluindo, além da escuta da subjetividade, a análise da inserção social do sujeito e suas potencialidades de transformaçãó ${ }^{20}$. 
Uma das hipóteses para essas dificuldades está ligada à angústia que as demandas de SM provocam nos profissionais que, sem recursos para lidar com elas, reagem defensivamente, com propostas de aplacamento dos sintomas.

Nesse sentido, é patente uma influência da Psiquiatria, em sua vertente biologicista, que propóe medicamentos como forma principal de tratamento e a utilização de manuais de classificação diagnósticos que definem os transtornos a partir de uma lista de sintomas, evitando a discussão de sua etiologia; transformando vivências e dificuldades cotidianas em doenças; e contribuindo para a desresponsabilização dos sujeitos com relação ao seu sofrimento ${ }^{21}$.

Outra dificuldade relaciona-se à visão de que a SM é uma especialidade exclusiva de psicólogos e psiquiatras, o que favorece a lógica de encaminhamento, principalmente ao Caps, sobrecarregando a atenção especializada ${ }^{15}$.

Essas dificuldades colocam um grande desafio para o Nasf na organização de estratégias que propiciem aos profissionais da APS maior familiarização no manejo clínico desses temas de acordo com o que é preconizado na proposta da Raps. Ela tem como diretrizes o respeito aos direitos humanos; a garantia da autonomia e da liberdade das pessoas; o combate a estigmas e preconceitos; o cuidado integral e a assistência multiprofissional sob a lógica interdisciplinar; a atenção humanizada e centrada nas necessidades das pessoas; a diversificação das estratégias de cuidado, entre outras ${ }^{19,22}$.

\section{Capacitação e EPS}

Com relação à capacitação, algumas equipes da APS mencionam processos pontuais sobre o manejo dos pacientes de SM, mas que ficaram "bem abaixo da expectativa". De maneira geral, os relatos relacionam-se à falta de preparo da eSF para lidar com as especificidades relacionadas à SM:

Então eu acho que nossa equipe não está preparada pra trabalhar com a parte de saúde mental. [...] eu acho que a gente tem que ter uma visão mais ampla em relação ao portador de saúde mental e como conduzi-lo e às vezes a gente fica sem saber o que fazer. (Enfermagem)

Muitas vezes, os profissionais da APS identificam casos na comunidade, mas não sabem como intervir. As dificuldades são ainda maiores com relação aos transtornos graves e momentos de crise, sendo que alguns profissionais expressam medo em lidar com situaçôes vinculadas à SM e o atribuem à falta de capacitação:

[...] às vezes ele já tem uma rejeição em procurar uma unidade de saúde, né, porque ele se sente retraído, e mais ainda nós, profissionais, por às vezes um despreparo não conseguimos acolher ele da forma que ele deveria ser acolhido. A gente fica às vezes com medo, ou às vezes a gente tem o próprio medo de não tá fazendo o que deveria ser feito realmente com ele [...]. (Enfermagem) 
O medo relatado pelos profissionais geralmente está associado ao preconceito e estigmatização sofridos por esses usuários e são pontos relevantes para ações de EPS. Percebe-se que há uma expectativa que a pessoa funcione como previsto e, quando ela reage diferente disso, o profissional não sabe o que fazer.

Nessas situações, a realização do apoio matricial, permitindo que a discussão do caso produza reflexão em toda a equipe, mostra-se uma ferramenta poderosa para aumentar a capacidade de acolhimento da equipe de $\mathrm{ESF}^{17}$.

Os profissionais percebem que os médicos generalistas não estão preparados para manejar casos de SM, mostrando dificuldades para diagnosticar, manejar as medicaçóes e acompanhar os casos; entretanto, eles dificilmente participam das capacitações oferecidas. Uma das razóes desse despreparo pode estar ligada às deficiências dos cursos de graduação, que, na maioria das vezes, não trata com profundidade os temas de $\mathrm{SM}^{19}$.

Estudos apontam que mesmo profissionais especialistas como psiquiatras e psicólogos apresentam essa dificuldade, pois os campos de prática em SM nas graduações e nas residências muitas vezes são estruturados em contextos muito distantes da APS. São modelos voltados para atuação individualizada, de longo prazo ou centrados em pacientes graves que perpetuam a lógica hospitalocêntrica e os modelos tradicionais de prática em saúde ${ }^{19,23}$.

Nesse sentido, identificam-se recentemente iniciativas de mudanças nas diretrizes curriculares, na graduação e residências, buscando um alinhamento com as necessidades do SUS ${ }^{23}$.

Os profissionais apontam a necessidade de capacitaçôes em temas específicos como o uso de psicotrópicos, depressão, ansiedade, conflitos familiares, violência doméstica, acolhimento em SM, tabagismo, outubro rosa e suicídio. A maioria não conhece a proposta de EPS e a demanda por formação acontece em uma perspectiva tradicional, estruturada a partir de intervençôes pontuais baseadas em um profissional detentor de saber.

Algumas equipes relatam que a equipe do Nasf já desenvolveu alguns temas como suicídio, síndrome de pânico, ansiedade, anorexia, bulimia, dependência química, Alzheimer e sequelas de AVC. No entanto, mencionam que essas açốes acontecem pontualmente. De maneira geral, as falas ressaltam a necessidade de aprofundamento das ações do Nasf, possibilitando à APS maior familiarização com a prática em SM:

Em saúde mental a gente, eu acho que, todos têm que ter um treinamento, pra justamente isso, essa questão da abordagem, como você vai abordar, como vai fazer a pergunta, de que forma você vai fazer, sabe? Eu acho que realmente a gente precisa muito. (Medicina)

Uma das tarefas principais dos profissionais do Nasf é contribuir na construção de uma política de EPS na $\mathrm{APS}^{5}$. Na região estudada, as experiências que podem ser chamadas de EPS estão em estágio inicial e parece não haver assimilação de seus conceitos, problema já apontado pela literatura nacional ${ }^{24}$. 
Outras pesquisas mostram que a EPS é uma proposta complexa que encontra várias dificuldades na implementação, uma vez que propõe realizar mudanças estruturais na dinâmica da equipe, no processo de trabalho e nas relaçốes de poder.

As dificuldades de sua condução se relacionam à falta de visão e apoio da própria gestão, diminuindo a autonomia das equipes, resistências dos próprios profissionais, falta crônica de recursos humanos, dificuldades em trabalhar com preconceitos ligados ao sofrimento psíquico e visão tradicional hospitalocêntrica do tratamento em $\mathrm{SM}^{3}$.

A EPS constitui uma proposta estratégica, pois propóe um aprendizado no e pelo trabalho, incorporando a prática educativa no cotidiano das eSF. Ela propõe a aprendizagem significativa a partir de situações concretas com um incentivo à participação de toda a equipe, levando em conta os conhecimentos e experiências anteriores.

Dessa maneira, a EPS favorece a interdisciplinaridade e integralidade da atenção em saúde, desenvolvendo a construção coletiva do saber inserida no contexto social. Seu êxito depende da imbricação entre processos educativos e processos de intervenção institucional que contemplem a complexidade dos vetores que envolvem a coprodução dos modos de fazer saúde ${ }^{17,25}$.

\section{A APS e o Nasf}

Apesar de o Nasf ser uma proposta de 2008, não há clareza sobre ela e sobre o papel do profissional de SM na equipe do Nasf, o que produz falsas expectativas e induz atuações com objetivos diferentes da proposta oficial. Há expectativa de que ele deveria disponibilizar uma agenda de atendimentos individuais na APS e ficar responsável unicamente por essas demandas.

Foi comum encontrarmos profissionais do Nasf desenvolvendo unicamente um trabalho clínico tradicional, com foco individualista, descontextualizado e sem interlocução com a equipe. Isso ocorre tanto em municípios maiores que possuem serviços especializados quanto em municípios de pequeno porte onde não existem outros profissionais da área de SM. Parece ser um problema tanto da gestão do município quanto de formação dos profissionais, cujos modelos formativos espelham e produzem um modelo hegemônico de atuação profissional, baseado no atendimento clínico liberal privativista ${ }^{18,26}$.

Na proposta do Nasf identificamos a aposta na Clínica Ampliada que inclui no processo a história do sujeito na sua dimensão individual e coletiva a partir das características do território em que vive. Ela não é centrada no sintoma e permite a discussão dos casos em espaços coletivos, possibilitando que a intervenção seja realizada por diferentes profissionais da equipe ${ }^{5,25}$.

Entre os participantes, várias são as críticas dirigidas aos profissionais da SM do Nasf: não trabalham em parceria com a equipe da APS, não participam da reunião de equipe, não fazem consulta compartilhada, não discutem casos em conjunto, não realizam visitas domiciliares e não participam de atividades externas às unidades.

[...] sou suspeita a falar do Nasf que eu acho que o trabalho dele, que era pra ser em conjunto com a equipe, ele é individualizado [...]. (Enfermagem) 
Na maioria dos municípios não acontecem reuniôes de matriciamento conforme as diretrizes do MS. Nas realidades em que ele acontece, geralmente um profissional expóe um caso para toda equipe discutir. A escolha dos casos a serem discutidos está relacionada com as dificuldades de atendimento, com a complexidade, gravidade e especificidade. Os profissionais relatam que, além dos espaços formais, existem interaçóes informais que acontecem no cotidiano do trabalho, nos intervalos dos atendimentos e até por telefone, seguindo a mesma lógica matricial.

A proposta do apoio matricial é fundamental no processo de implantação de ações de SM na APS, pois contribui para as mudanças no processo de trabalho na medida em que transfere tecnologias de cuidado para os profissionais, propóe um espaço interdisciplinar e de corresponsabilização que amplia o foco de intervenção e diminui os encaminhamentos desnecessários aos Caps, evitando a fragmentação da atenção e a medicalização.

O compartilhamento dos casos é fundamental na consolidação das redes e na mudança da cultura manicomial ${ }^{17,22}$. O apoio matricial deve ser pensado na complexidade da Raps e como dispositivo que pode abranger diversos níveis de atenção, tendo o Caps como um importante articulador do cuidado em SM que, na medida que se aproxima da APS, favorece o cuidado integral, promovendo reinserção social e fortalecendo laços familiares e comunitários 5 .

No entanto, estudo de revisão ${ }^{16}$ apontou desafios para a consolidação e efetividade do apoio matricial em SM, destacando obstáculos estruturais que permeiam a falta de uniformidade na estruturação dos serviços; necessidade de esclarecer o papel dos profissionais na proposta; fragmentação da rede; e burocratização do fluxo entre os serviços e os obstáculos subjetivos e culturais dos profissionais selecionados para o trabalho em SM.

Além disso, a ausência dos ACS nas discussóes de caso; as ocasióes em que o matriciamento é visto como atividade secundária e esvaziado; a carência de recursos; e, por fim, o obstáculo epistemológico, em que existe uma falta tanto de delineamento claro sobre as estratégias do matriciamento, coordenação dos casos e seguimento longitudinal quanto de conhecimento e/ou formação específicas para o desenvolvimento do trabalho a ser realizado.

O PTS ainda não havia sido assimilado na maioria das equipes e as poucas que o realizam, o fazem para casos mais graves, mas sem formalização e acompanhamento periódico do desenvolvimento da proposta.

Em alguns municípios, são desenvolvidos grupos de hipertensos, diabéticos, terceira idade, controle de peso, gestante, puericultura, crochê, artesanato e outros mais diretamente ligados à SM, como os grupos voltados para dependência química, ansiedade e depressão. Os profissionais relatam que a oferta de grupos específicos na área de SM enfrenta resistência da população e tem baixa adesão.

Os principais motivos alegados são a falta de privacidade na atividade grupal; a crença de que a medicação resolverá o problema; a falta de empatia do profissional de SM e a falta de capacitação do profissional do Nasf para a condução da prática grupal: 
[...] eu acho que a maioria dos grupos tem pouca adesão. Parece que os pacientes gostam mesmo é daquela filosofia de consultório, quer consultar, quer ter aquela consulta individualizada, parece ter um preconceito com atendimento grupal. (Enfermagem)

No sentido de desconstruir a cisão entre SM e saúde física, a atividade em grupo se apresenta como um dispositivo que permite aos usuários se colocarem como sujeitos e agentes de sua saúde, tornando-se corresponsáveis pelo seu tratamento. Além de auxiliar na construção de laços socais, o dispositivo grupal atua para que se supere a identificação dos sujeitos com a doença e com a concepção de uma cura restrita à solução medicamentosa ${ }^{14}$.

Essa resistência da população à participação dos grupos em SM não se deve exclusivamente a um "problema” dos usuários ou de capacitação dos profissionais, individualmente, mas principalmente à restrição e/ou baixa qualidade da oferta de atividades coletivas baseadas na lógica da clínica ampliada e da corresponsabilização, bem como à ausência de políticas de EPS ${ }^{17,25}$.

\section{A estruturação da Raps}

Quanto à organização da Raps, os profissionais mencionam problemas ligados à gestão; dificuldades na comunicação entre os serviços e falta de espaços regulares para a construção dessa integração; e inexistência de protocolos para que se tenha clareza dos casos que devem ser encaminhados para o Caps e dos casos que devem ser acompanhados na APS.

Constata-se falta de opçôes de encaminhamento dos usuários em situações de crise, ficando patente nesses casos um isolamento da eSF. Na maioria dos municípios, o psiquiatra está presente somente no Caps e esse suporte é insuficiente, devido à dificuldade de agendamento de consultas.

Foi ressaltado que os médicos da APS, na maioria das vezes, não conseguem fazer contato com o psiquiatra do Caps, mesmo nos casos graves. Na ausência de articulação com o Caps, a APS recorre às Unidades de Pronto Atendimento (UPAs) e hospitais psiquiátricos ainda existentes no estado.

Essas falas demonstram uma visão regional de cuidado ainda centrado na figura do médico, mesmo nos Caps:

O paciente fica solto, né, e aí como que a gente faz? Se ele tá bem não tá tomando medicação, se ele não toma medicação ele tem surto e acaba indo pra UPA, né? Vai pra UPA fazer a medicação lá, mas não resolve o problema. (Enfermagem)

Entretanto, em alguns municípios que possuem Caps, os profissionais identificam o trabalho como positivo, auxiliando no manejo da SM e na diminuição das internaçóes hospitalares. Há pouca regularidade das reuniôes da APS com o Caps, mas estas ajudam a esclarecer a forma de trabalho e muitas vezes acontecem atendimentos conjuntos. Há uma percepção de que o Caps é sobrecarregado, com excesso de usuários. 
Com relação aos pacientes egressos de internação, os profissionais mencionam que eles são acompanhados pela APS, mas também seguem o fluxo de consultas com o psiquiatra, apontando novamente falta de autonomia da APS para condução dos casos de SM. Há relatos de resistência de usuários e familiares em procurar o Caps pelo receio de estigmatização.

Nos municípios menores que não possuem Caps, mas que possuem Caps de referência em um município maior dentro da Região de Saúde, existe uma tendência a não utilizá-lo como retaguarda para casos graves, optando-se pelo atendimento de urgência nos serviços do próprio município e, em seguida, o encaminhamento direto para os hospitais psiquiátricos.

Isso acontece também nos casos relacionados à dependência química, pois o Caps de referência muitas vezes se recusa a recebê-los. Para casos graves de dependência química, a ausência de Caps $\mathrm{AD}$ favorece o encaminhamento para as comunidades terapêuticas da região.

Outra dificuldade refere-se à retaguarda de SM para o público infantil, pois o Caps é reticente em absorvê-la. Alguns pediatras da rede dão apoio à criança e aos familiares alegando, entretanto, não ter capacitação para esse tipo de atendimento.

A Raps se caracteriza por relaçóes horizontais entre os diversos pontos de atenção, tendo a APS como articuladora. O processo de construção dessas redes é complexo, pois envolve gestão, serviços e profissionais, no sentido de estabelecer canais de comunicação, propor um fluxo e uma lógica de ação de modo que os usuários sejam atendidos de maneira integral ${ }^{6,22}$.

A falta de apoio do Caps à APS com relação aos casos mais graves e a fragilidade em lidar com essas questóes de SM dos municípios produzem um sentimento de descrença dos profissionais na efetividade da rede e contribuem para a busca de soluçôes isoladas.

A gestão deve ter um papel ativo nesse processo, promovendo condições e suporte para que os profissionais possam se reunir, definindo objetivos e metas claras a serem alcançadas e propondo fluxos e protocolos, sendo seu papel a implementação do apoio matricial e de políticas e açốes de EPS ${ }^{3,22}$.

Por fim, consideramos que o caráter inovador da investigação se sustenta ao dar voz a municípios de pequeno e médio porte, que normalmente não contam com uma forte retaguarda em SM, além de envolver muitos profissionais de diversas áreas atuantes na APS de uma macrorregião de saúde, mostrando que a Raps é uma construção de parcerias regionais.

\section{Considerações finais}

Em síntese, os principais desafios na abordagem das demandas em SM na realidade estudada estão relacionados à falta de EPS; dificuldades na articulação entre serviços e na definição de estratégias de atuação pautadas em um processo de trabalho em saúde mais integrado. 
Apesar das fragilidades, há indícios de novas reflexões em direção à mudança da lógica tradicional biomédica de cuidados em saúde na medida que os profissionais começam a considerar a relação entre vulnerabilidade social e sofrimento psíquico e a abordagem dos sujeitos em seus contextos.

Nessa perspectiva, é possível perceber que os profissionais estabelecem reflexôes e críticas mais amplas em relação aos vários problemas discutidos, a exemplo do crescente consumo de medicamentos psicotrópicos; dos problemas de violência familiar; e da importância da família para a abordagem de situaçôes de crise em SM e para a abordagem e manejo das questôes relacionadas ao abuso de álcool e drogas.

Essa ampliação da percepção das demandas em SM se faz atrelada à ampliação da percepção dos profissionais sobre a necessidade de capacitação, de condições de trabalho e de uma organização do trabalho que os ajude a lidar com a complexidade de situaçôes que exigem não somente o foco de atenção nos sujeitos de forma isolada, mas também uma atenção que considere os grupos familiares dos quais fazem parte, sua cultura e as condiçôes de vida que os inscrevem em situaçôes de risco e vulnerabilidade.

Vale destacar que, em 2019, o MS alterou a forma de credenciamento do Nasf, ampliando o poder de decisão dos municípios, o que, de certa forma, pode levar à descontinuidade das equipes já existentes. Esse fato ressalta a importância de estudos que apontem a importância das mudanças pretendidas pela criação do Nasf, como apontado na discussão.

Apesar de este estudo se constituir como um primeiro mapeamento da realidade de municípios da região pesquisada, ressalta-se que suas limitaçôes estão circunscritas ao caráter dinâmico dessas realidades e do tipo de mudanças de organização do setor saúde em curso no país, que podem representar um processo de fragilidade das novas práticas em SM na APS.

Nesse sentido, novos desenhos de pesquisa que permitam o aprofundamento dos aspectos levantados, bem como acompanhamento das mudanças dessas realidades pesquisadas, são necessários. 


\section{Contribuição dos autores}

Todos os autores participaram ativamente de todas as etapas de elaboração do manuscrito.

\section{Financiamento}

Financiado pela Fundação de Amparo à Pesquisa do Estado de Minas Gerais (FAPEMIG), edital 01/2016, demanda universal processo n. CHE-APQ-02530-16, e edital 03/2020 PIBIC/UFSJ.

\section{Agradecimentos}

À Universidade Federal de São João del Rei (UFSJ) e Superintendência Regional de Saúde da Secretaria Estadual de Saúde de Minas Gerais (SRS/SES/MG).

\section{Conflito de interesse}

Os autores não têm conflito de interesse a declarar.

\section{Direitos autorais}

Este artigo está licenciado sob a Licença Internacional Creative Commons 4.0, tipo BY (https://creativecommons.org/licenses/by/4.0/deed.pt_BR).

\section{(cc) BY}

\section{Editora}

Rosana Teresa Onocko Campos

Editor associado

Tiago Rocha Pinto

\section{Submetido em}

24/06/20

Aprovado em

$01 / 12 / 20$

\section{Referências}

1. Wenceslau LD, Ortega F. Mental health within primary health care and Global Mental Health: international perspectives and Brazilian context. Interface (Botucatu). 2015; $19(55): 1121-32$.

2. World Health Organization. WONCA. Integrating mental health in primary care: a global perspective [Internet]. Geneva: WHO; 2008 [citado 23 Jun 2020]. Disponível em: https://www.who.int/mental_health/resources/mentalhealth_PHC_2008.pdf

3. Lima WAL, Christo SAC, Machado CJ. Atenção psicossocial além da Reforma Psiquiátrica: contribuições a uma Clínica Crítica dos processos de subjetivação na Saúde Coletiva. Cienc Saude Colet. 2016; 21(10):3309-10. 
4. Brasil. Ministério da Saúde. Saúde mental e atenção básica: o vínculo e o diálogo necessários [Internet]. Brasília: Ministério da Saúde; 2007 [citado 23 Jun 2020]. Disponível em: https://www.nescon.medicina.ufmg.br/biblioteca/imagem/1734.pdf

5. Brasil. Ministério da Saúde. Portaria no 154, de 24 de Janeiro de 2008. Cria os Núcleos de Apoio à Saúde da Família - NASF [Internet]. Brasília: Ministério da Saúde; 2008 [citado 23 Jun 2020]. Disponível em: http://bvsms.saude.gov.br/bvs/saudelegis/ gm/2008/prt0154_24_01_2008.html

6. Brasil. Ministério da Saúde. Portaria no 3.088, de 23 de Dezembro de 2011. Institui a Rede de Atenção Psicossocial para pessoas com sofrimento ou transtorno mental e com necessidades decorrentes do uso de crack, álcool e outras drogas, no âmbito do Sistema Único de Saúde (SUS) [Internet]. Brasília: Ministério da Saúde; 2011 [citado 23 Jun 2020]. Disponível em: http://bvsms.saude.gov.br/bvs/saudelegis/gm/2011/ prt3088_23_12_2011_rep.html

7. Minayo MCS, Deslandes SF, Cruz Neto OGR. Pesquisa social: teoria, método e criatividade. 34a ed. Petrópolis: Vozes; 2015.

8. Departamento de Informática do SUS - Datasus. Informações demográficas e socioeconômicas: banco de dados [Internet]. Brasília: Ministério da Saúde; 2017 [citado 23 Jun 2020]. Disponível em: http://tabnet.datasus.gov.br/cgi/tabcgi.exe?ibge/cnv/poptm

9. Gama CAP, Guimarães DA, Coelho VAA, Carvalho RC, Campos CG, Fraga AMS. A implantação da rede de atenção psicossocial na Região Ampliada de Saúde Oeste de Minas Gerais-BR. Cad Saude Colet. 2020; 28(2):278-87.

10. Pope C, Mays N. Pesquisa qualitativa na atenção à saúde. 3a ed. Porto Alegre: Artmed; 2009.

11. Paim JS, Almeida Filho N. Saúde coletiva: uma "nova saúde pública” ou campo aberto a novos paradigmas? Rev Saude Publica.1998; 32(4):299-316.

12. Bezerra B. Desafios da reforma psiquiátrica no Brasil. Physis. 2007; 17(2):243-50.

13. Campos GWS. Saúde Paidéia. 3a ed. São Paulo: Hucitec; 2007.

14. Minozzo F, Kammzetser CS, Debastiani C, Fait CS, Paulon SM. Grupos de saúde mental na atenção primária à saúde. Fractal Rev Psicol. 2012; 24(2):323-40.

15. Gonçalves RC, Peres RS. Matriciamento em saúde mental: obstáculos, caminhos e resultados. Rev SPAGESP. 2018; 19(2):123-36.

16. Treichel CAS, Campos RTO, Campos GWS. Impasses e desafios para consolidação e efetividade do apoio matricial em saúde mental no Brasil. Interface (Botucatu). 2019; 23:e180617.

17. Campos GWS, Figueiredo MD, Pereira N, Castro CP. A aplicação da metodologia Paideia no apoio institucional, no apoio matricial e na clínica ampliada. Interface (Botucatu). 2014; 18(1):983-95.

18. Melo MIS, Galindo WCM. O trabalho como residente de psicologia em equipe do Núcleo de Apoio à Saúde da Família (NASF). Pesqui Prat Psicossociais. 2018; 13(4):e1143.

19. Rotoli A, Silva MRS, Santos AM, Oliveira AMN, Gomes GC. Saúde mental na Atenção Primária: desafios para a resolutividade das açốes. Esc Anna Nery Rev Enferm. 2019; 23(2):e20180303.

20. Val AC, Modena CM, Campos RTO, Gama CAP. Psicanálise e Saúde Coletiva: aproximaçốes e possibilidades de contribuiçốes. Physis. 2017; 27(4):1287-307.

21. Martinhago F, Caponi S. Controvérsias sobre o uso do DSM para diagnósticos de transtornos mentais. Physis. 2019; 29(2):e290213. 
22. Peres GM, Crepaldi MA, Motta CCL, Grigolo TM. Limites e desafios da rede de atenção psicossocial na perspectiva dos trabalhadores de saúde mental. Cad Bras Saude Ment. 2018; 10(27):34-52.

23. Ceccim RB, Feuerwerker LCM. Mudança na graduação das profissões de saúde sob o eixo da integralidade. Cad Saude Publica. 2004; 20(5):1400-10.

24. Penido CMF, Passos ICF, Andrade IC. Saúde mental e Estratégia de Saúde da Família: uma primeira experiência de aproximação. Gerais. 2015; 8(2):258-68.

25. Lopes SRS, Piovesan ETA, Melo LO, Pereira MF. Potencialidades da educação permanente para a transformação das práticas de saúde. Comun Cienc Saude. 2007; 18(2):147-55.

26. Tesser CD. Núcleos de Apoio à Saúde da Família, seus potenciais e entraves: uma interpretação a partir da atenção primária à saúde. Interface (Botucatu). 2017; 21(62):565-78.

Mental Health (MH) in Primary Health Care is complex and requires the integration of actions across various levels of care. This study sought to understand how primary care professionals in 11 municipalities in Minas Gerais with family health centers (FHC) deal with MH demands. We conducted a qualitative study with focus groups made up of 134 health professionals. The professionals were not equipped with tools or strategies to quantify and organize $\mathrm{MH}$ demands; $\mathrm{MH}$ training was insufficient; the professionals reported difficulties implementing FHC proposals and problems in the organization and coordination of the psychosocial care network, compromising the continuity of $\mathrm{MH}$ care. Despite the weaknesses identified by this study, there are signs of a shift in the traditional biomedical logic of health care.

Keywords: Mental Health. Primary Health Care. Matrix support. Permanent Health Education. Comprehensive health care.

La atención de la salud mental (SM) en la Atención Primaria de la Salud (APS) es compleja y demanda integración de las acciones entre diversos niveles de atención para mayor efectividad. Se buscó entender cómo profesionales de la APS de 11 municipios del Estado de Minas Gerais que tenían Núcleo de Atención de la Salud de la Familia (NASF), enfrentaban las demandas de SM. Se trata de un estudio cualitativo realizado por medio de grupos focales que contaron con 134 profesionales de salud. Los profesionales no tenían instrumentos o estrategias para cuantificar y organizar la demanda de SM; las acciones de capacitación en SM eran insuficientes; relataron dificultades en la implementación de las propuestas del NASF; identificaron problemas en la organización y articulación de la Red de Atención Psicosocial (RAPS) que perjudicaban la continuidad del cuidado en SM. A pesar de las fragilidades presentadas, hay reflexiones sobre los cambios de la lógica tradicional biomédica en cuidados de la salud.

Palabras clave: Salud mental. Atención primaria de la salud. Apoyo matricial. Educación permanente en salud. Integralidad en salud. 